J. Dräseke: Zu den „Inschriften aus Syrien“ usw. B. Z. XIV, S. 21-26 587

Aristeides beweist, der sich 13 Jahre lang an den verschiedenen Heiligtümern als „ewiger Inkubant" herumgetrieben hat. Beachten wir dazu noch den Umstand, daB die Alten nicht bloB persönlich die Gottheit befragten, sondern auch durch stellvertretende, gleichfalls xór sessene" genannte Orakelsucher, die als Glieder einer besonderen Gilde erscheinen, durch Tempelschlaf den Willen des Gottes erkundeten, so haben wir diejenigen Stücke der Überlieferung beisammen, die zur richtigen Beurteilung des Sinnes der genannten Inschriften nötig sind. Ich selbst habe dann in AnschluB an die von Preuschen in bezug auf

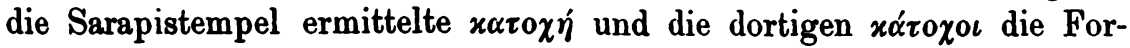
schung weiterzuführen gesucht und in meinem Aufsatz „Zum Untergang des Heidentums" (Z. f. w. Th. XLIV, S. 74-86) nach des Markos Diakonos Bericht in seiner Vita Porphyrii die gleichen religiösen Verhältnisse, wie sie in Memphis und Baitokaike bestanden, auch in Gaza von den Tempeln der Aphrodite und des Marnas nachgewiesen.

Wandsbeck, 9. März 1905.

Johannes Dräseke.

\title{
Contributo alle „Inschriften” aus Syrien“ B. Z. XIV.
}

L' iscrizione p. 31 no. 23 è composta con emistichii dal c. 4 del cantico dei cantici. Nella linea antepenultima e segg. si ha da supplire

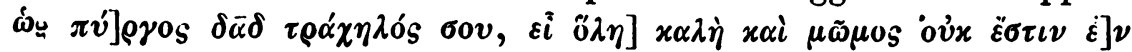
$\sigma 0 i+(4,4.7)$.

In fine alla ultima linea pare convenga $\left.\dot{\omega}_{S} \sigma \pi \alpha 0\right] \pi i o v$ (cf. v. 3)

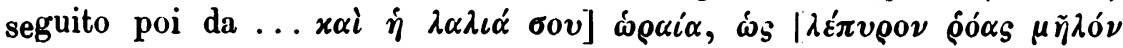
бov. $\left.\dot{\omega}_{S} \pi \dot{v}\right] \rho \gamma o s$ etc.

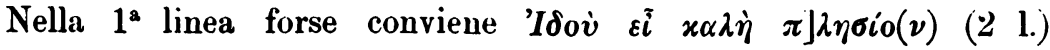
$[\mu 0 v \ldots$ v. 1$)$.

Dalla linea ultima parrebbe risultare che le linee contenessero circa una ventina di lettere, ma non ne sono sicuro, e quindi dubito della precisione di qualche supplemento proposto sopra, foudato sul testo attuale della cantica. $\grave{\mathbf{E}}$ da notare che nel v. $T$ è supposta la variante del cod. 300 di Holmes-Parsons (Vulg. "O $O \lambda \eta x \alpha \lambda \grave{\eta} \varepsilon \dot{i} \pi \lambda \eta \sigma i o \nu$ $\mu \rho v \varkappa . \mu \tilde{\omega} \mu 0 s \quad x \tau \lambda$.). A p. 37 n. $38 c$ il vero luogo del Salterio è Ps. i0 (71) 30 , non 30 (31) 3 .

Roma.

G. Mercati. 